\title{
Perancangan dan Realisasi Pengatur Kadar Garam pada Aquarium Air Laut Berbasis Mikrokontroler ATMEGA16
}

\author{
Paryanta $^{* 1}$, Widyo Ari Utomo ${ }^{2}$, Deta Wahyu Herlambang ${ }^{3}$ \\ ${ }^{1}$ Program Studi Teknik Komputer, STMIK AUB, Surakarta, Indonesia \\ ${ }^{2,3}$ Program Studi Sistem Komputer, STMIK AUB, Surakarta, Indonesia \\ e-mail: *1paryanta@stmik-aub.ac.id, ${ }^{2}$ widyo.ari@stmik-aub.ac.id, ${ }^{3}$ deta.wahyu.dw@gmail.com
}

\begin{abstract}
Abstrak
Aquarium sea water is a place to keep the fish that live in sea water. Setting levels of salt in the water is one of the problems that often occur. The intensity of the impact on the salt content of appetite that can lead to stress fish so that the fish will die. This thesis will be made the design and realization of the regulator saline seawater aquarium. The main characteristics of the sensor voltage values salinity is issued is inversely proportional to the value of the water levels are detected. If the salt content the higher the voltage value becomes lower. The sensors used in the form of parallel metal pieces which serves as a detector of the change in resistance. The output of the censor will be the input to the ADC. While calculations using ATmegal6 microcontroller and the result is displayed on the LCD. If the value of the salt content of sea water aquarium turned microcontroller ATmegal6 control valves salt water and fresh water faucet to stabilize the salinity at a certain value. With this thesis is realized, it is expected to reduce the problems in the maintenance of saltwater fish.
\end{abstract}

Kata kunci: Salinity, LCD, Microcontroller ATmega16

\section{PENDAHULUAN}

Tingkat kadar garam air menjadi masalah bagi pemelihara ikan akuarium air laut, karena dapat mengakibatkan kematian biota dalam aquarium. Tingkat kadar garam berdampak terhadap kelangsungan hidup plangton yang menjadi makanan ikan dan menurunkan nafsu makan ikan yang dapat berakibat stress serta matinya ikan. Untuk mengatasi hal tersebut dapat dirancang dan dibuat pengatur kadar air garam berbasis Mikrokontroler ATMega16. Ketika proses pendeteksian, nilai resistansi dideteksi oleh metal keping sejajar yang dicelupkan ke dalam aquarium. Nilai resistansi ini akan menghasilkan tegangan yang kemudian akan diproses oleh Analog to Digital Converter (ADC) sebagai masukan mikrokontroler yang hasilnya akan ditampilkan pada Liquid Crystal Display (LCD). Bila kondisi kadar garam dalam aquarium tinggi maka secara otomatis akan menambahkan air tawar sedangkan kondisi kadar garam yang rendah akan menambahkan air laut sehingga kandungan garam yang ada dalam aquarium dapat kembali normal.

Pengaturan sistem menggunakan mikrokontroller ATMEGA16, dimana atmel ini merupakan mikrokontroler 8 bit dengan $16 \mathrm{~KB}$. Piranti ini menggunakan teknologi memori tak sumirna, kepadatan tinggi, dan kompatibel dengan pin out dan set instruksi standar industri INTEL. Plant yang digunakan dalam penelitian adalah aquarium. Ruang lingkup penelitian ini antara lain: aquarium air laut yang dipakai adalah berupa miniatur, mikrokontroler yang digunakan sebagai kendali adalah ATMEGA16, tampilan nilai kadar garam menggunakan LCD. Dengan adanya masalah dan persoalan diatas maka penulis membuat judul skripsi "Perancangan dan Realisasi Pengatur Kadar Garam pada Aquarium Air Laut Berbasis Mikrokontroler Atmega16".

Received May 6, 2019; Revised May 27, 2019; Accepted June 12, 2019 


\section{METODE PENELITIAN}

\subsection{Diagram Blok}

Agar memudahkan dalam memahami cara kerja dari alat maka dibuatlah diagram blok rangkaian, yang dapat dilihat pada gambar 1 dibawah ini.

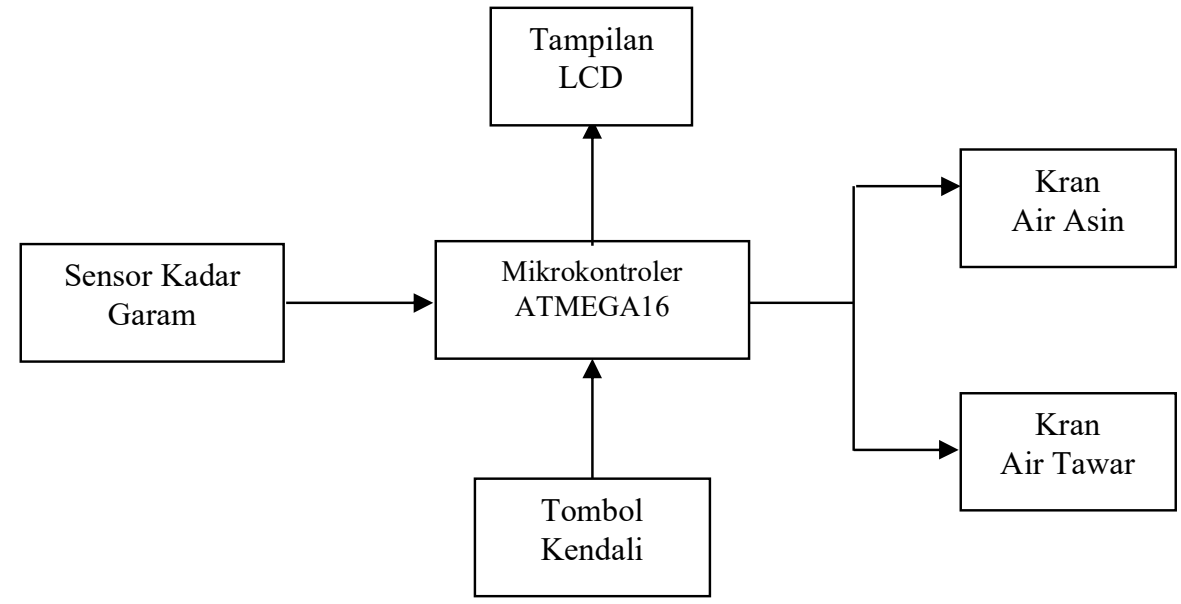

Gambar 1 Diagram Blok

Sensor kadar garam digunakan untuk mendeteksi kadar garam yang ada pada aquarium air laut. Mikrokontroler ATMEGA16 digunakan untuk mengukur nilai kadar garam dari sensor, mengolahnya dan menampilkan hasil pengukurannya pada tampilan LCD. Jika nilai kadar garam dari aquarium air laut berubah maka mikrokontroler ATMEGA16 mengendalikan kran air asin dan kran air tawar untuk menstabilkan nilai kadar garam pada nilai tertentu.

\subsection{Perancangan Rangkaian Catu Daya}

Fungsi dari rangkaian catu daya adalah untuk memenuhi kebutuhan daya dari alat. Adapun skema dari rangkaian catu daya dapat dilihat pada gambar 2 dibawah ini.

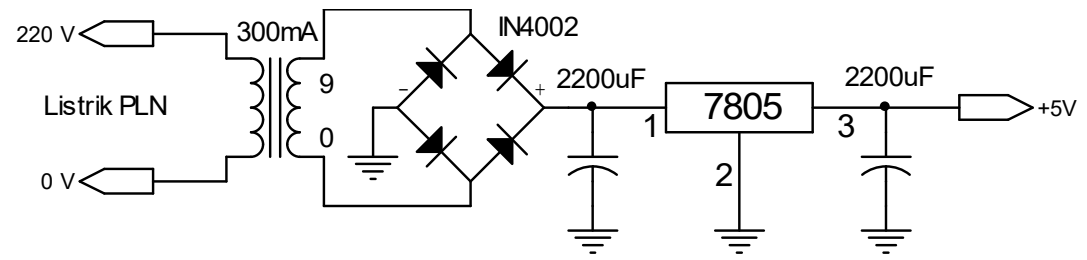

Gambar 2 Rangkaian Catu Daya

\subsection{Perancangan Rangkaian Sensor Kadar Garam}

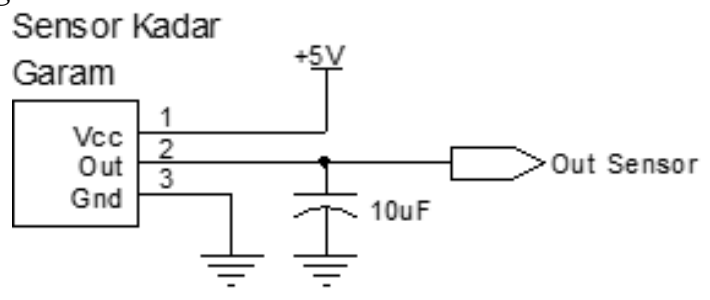

Gambar 3 Rangkaian Sensor Kadar garam

Sensor menggunakan dua buah metal keping sejajar yang memiliki catu daya sebesar $5 \mathrm{~V}$ dan satu buah kapasitor $10 \mathrm{uF}$ yang digunakan untuk menyimpan arus listrik sementara. Karakteristik utama dari sensor kadar garam adalah nilai tegangan yang dikeluarkan adalah berbanding terbalik dengan nilai kadar dari air yang dideteksi. Jika kadar garam semakin tinggi maka nilai tegangan menjadi semakin tinggi.

2.4. Rangkaian Mikrokontroler ATMEGA16

GO INFOTECH: JURNAL ILMIAH STMIK AUB Vol. 25, No. 1, Juni 2019 : 35 - 42 


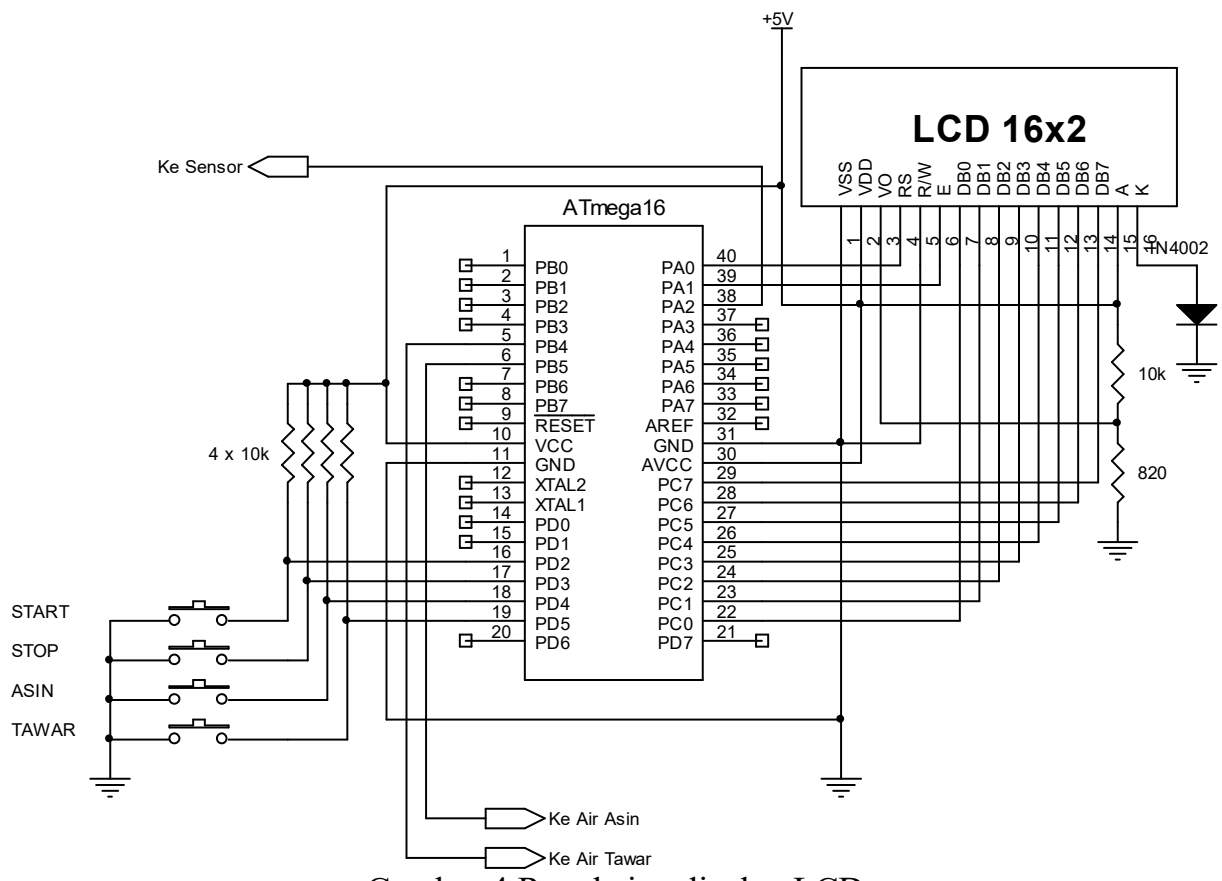

Gambar 4 Rangkaian display LCD

Rangkaian display LCD memerlukan daya sebesar 5v dan menggunakan 1 buah resistor berukuran 10k dan 820 yang digunakan untuk menahan arus pada rangkaian. Tegangan bolakbalik ini kemudian disearahkan dengan menggunakan 1 buah dioda penyearah seri IN4002. Satu Mikrokontroler ATMega16 digunakan untuk mengolah data yang akan ditampilkan diLCD. Empat buah tombol saklar digunakan untuk mengendalikan alat yang masing-masing menggunakan resistor $10 \mathrm{k}$ untuk menahan arus.

2.5. Rangkaian Kendali Keran Air Asin atau Air Tawar

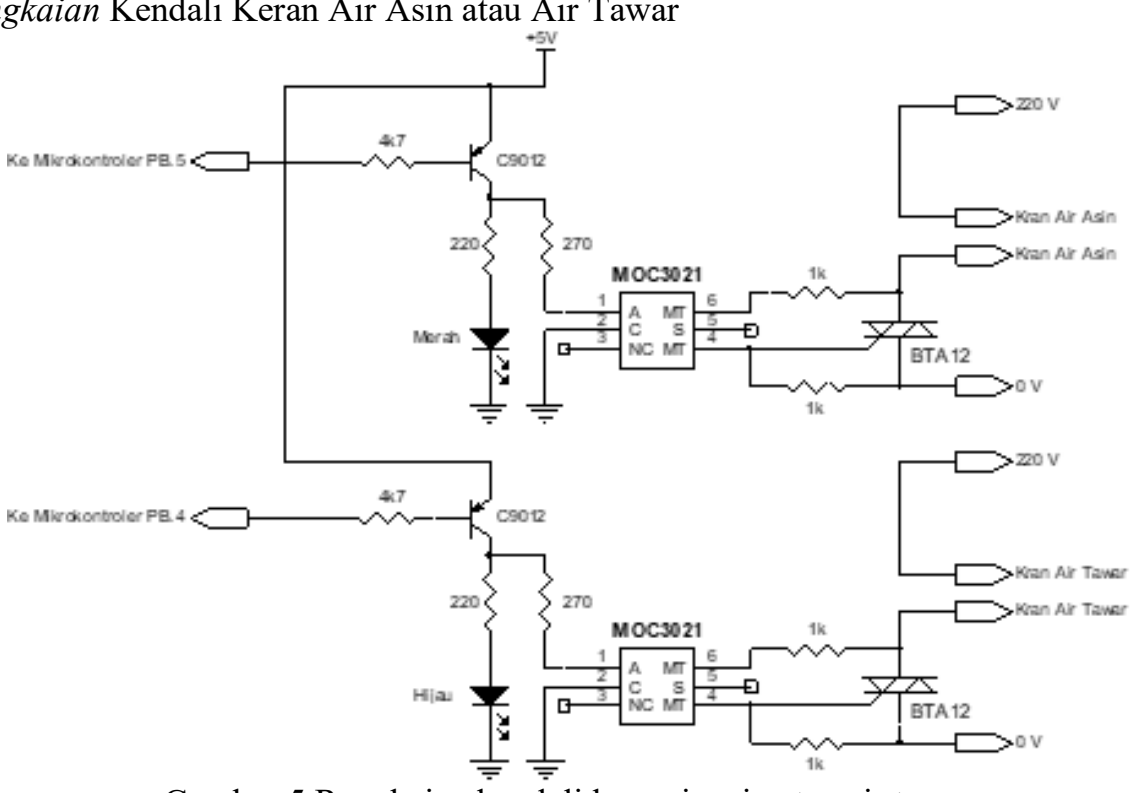

Gambar 5 Rangkaian kendali kran air asin atau air tawar

Dua buah triac seri BTA12 digunakan sebagai sakelar elektronik yang akan menghubungkan dan mematikan kran otomatis dari sumber listrik. 


\section{HASIL DAN PEMBAHASAN}

\subsection{Cara Kerja Alat}

1. Hubungkan catu daya ke sumber listrik.

Pada gambar 6 dibawah menjelaskan cara menghubungkan catu daya dengan sumber listrik atau terminal listrik.

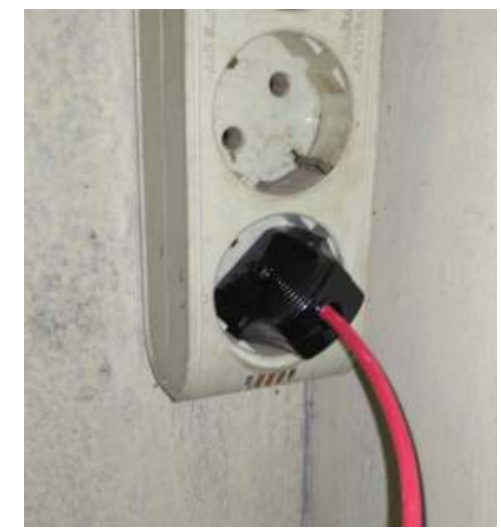

Gambar 6 Hubungan catu daya ke sumber listrik

2. Tekan tombol kendali ON untuk memulai.

Pada gambar 7 dibawah menjelaskan tentang cara kerja menggunakan tombol ON OFF. Tombol disini digunakan untuk menghidupkan arus listrik dari catu daya yang akan dialirkan ke rangkaian sensor dan rangkaian pada mikro dengan cara ditekan.

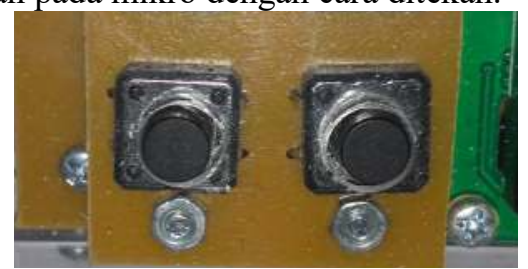

Gambar 7 Cara Kerja Tombol Kendali

3. Masukkan Sensor kedalam akuarium.

Gambar 8 dibawah menjelaskan tentang cara kerja memasukkan sensor pada akuarium. Letakkan sensor dalam posisi berdiri tegak dan pelat alumunium berada di bawah.

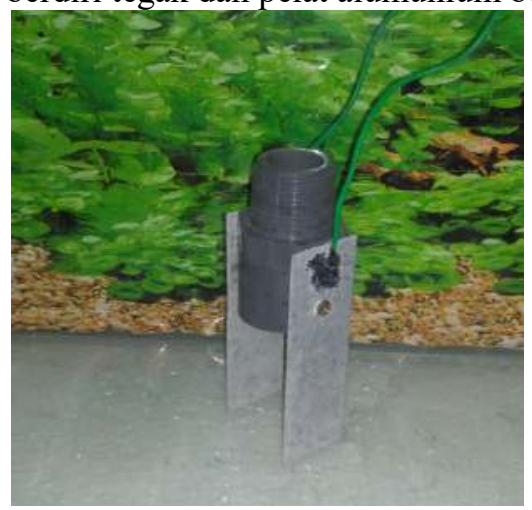

Gambar 8 Cara Kerja Sensor

4. Pengisian air pada akuarium.

Gambar 9 dibawah menjelaskan tentang pengisian air pada akuarium. Masukkan air tawar dan air laut pada akuarium sampai sensor tenggelam seluruhnya. 


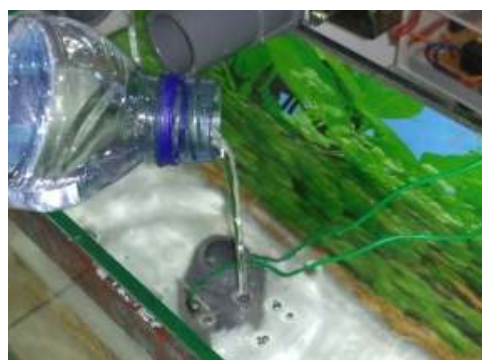

5. Pembacaan kadar garam.

Gambar 9 Pengisian Air Pada Akuarium

Gambar 10 dibawah menjelaskan tentang proses pembacaan kadar garam pada sensor mulai berjalan dan ditampilakn diLCD. Karakteristik utama dari sensor kadar garam adalah nilai tegangan yang dikeluarkan berbanding terbalik dengan nilai kadar dari air yang dideteksi. Jika kadar garam semakin tinggi maka nilai tegangan menjadi semakin tinggi.

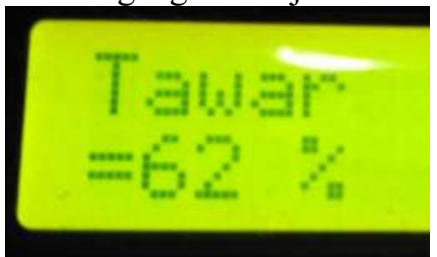

Gambar 10 Pembacaan Kadar Garam

6. Masukkan nilai referensi pada tombol kendali.

Masukkan nilai referensi nilai kadar garam pada tombol kendali dengan cara ditekan dan nilai referensi akan ditampilkan di LCD.

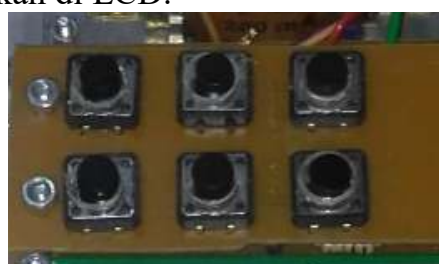

Gambar 11 Tombol Kendali

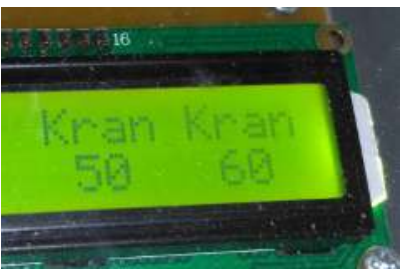

Gambar 12 Tampilan Nilai Referensi Pada LCD

7. Membandingkan nilai referensi.

Mikrokontroler akan membandingkan nilai referensi dengan nilai kadar garam yang diterima dari sensor. Jika nilai kadar tawar melebihi nilai refrensi maka mikrokontroler akan melakukan aksi menghidupkan keran air asin dan menambahkan air asin pada akuarium dengan ditandai menyalanya lampu LED berwarna merah.

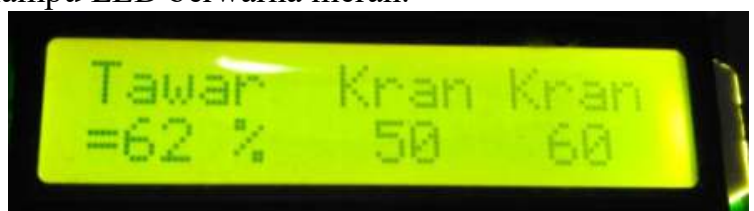

Gambar 13 Tampilan Nilai Kadar Tawar Melebihi Referensi

Perancangan dan Realisasi Pengatur Kadar Garam pada Aquarium Air Laut Berbasis Mikrokontroler ATMEGA16 (Paryanta) 


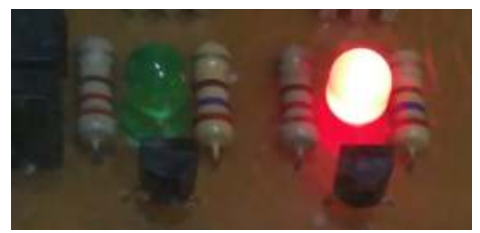

Gambar 14 Kondisi LED Menambahkan Air Asin

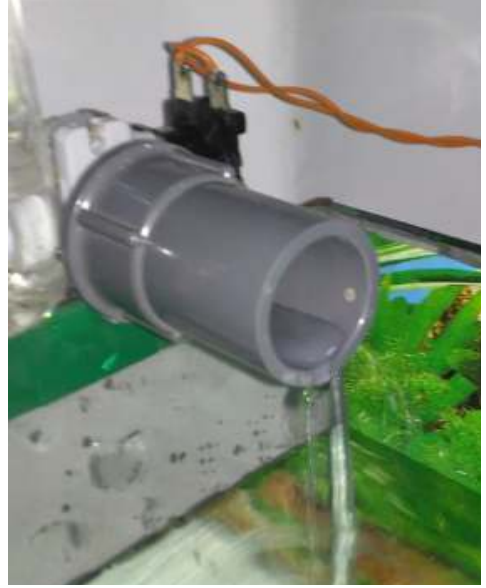

Gambar 15 Kondisi Keran Menambahkan Air Asin

Jika nilai kadar tawar kurang dari nilai refrensi maka mikrokontroler akan melakukan aksi menghidupkan keran air tawar dan menambahkan air tawar pada akuarium dengan ditandai menyalanya lampu LED berwarna hijau.

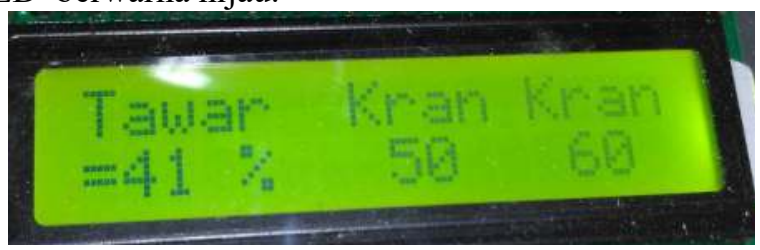

Gambar 16 Tampilan Nilai Kadar Tawar Melebihi Referensi

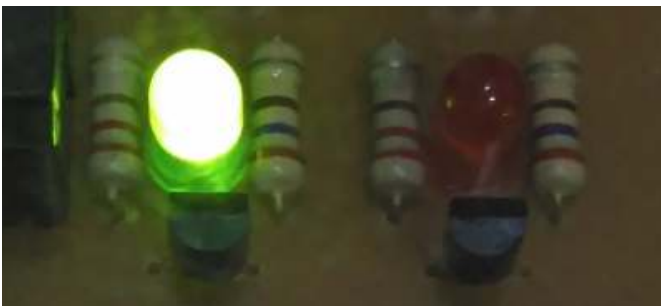

Gambar 17 Kondisi LED Menambahkan Air Tawar 


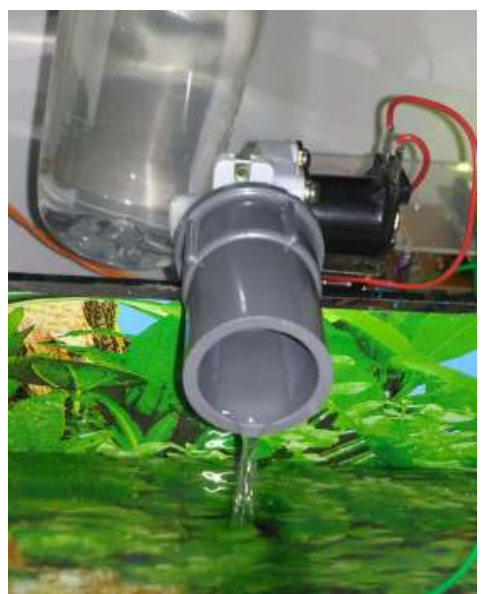

Gambar 18 Kondisi Keran Menambahkan Air Tawar

8. Keran air tawar dan keran air asin akan hidup dan mati otomatis.

Gambar 19 dibawah menjelaskan tentang Mikrokontroler akan terus membaca sensor dan membandingkan nilai kadar air tawar dengan nilai referensi yang akan ditampilkan pada LCD. Jika nilai sesuai dengan referensi maka mikrokontroler akan melakukan aksi untuk mematikan semua keran dengan ditandai lampu LED tidak ada yang menyala. Proses ini akan berlangsung berulang-ulang.

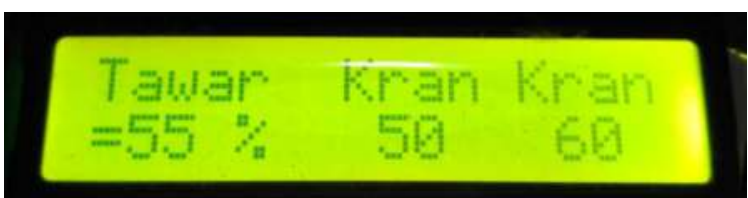

Gambar 19 Tampilan Nilai Kadar Tawar diantara range Nilai Referensi

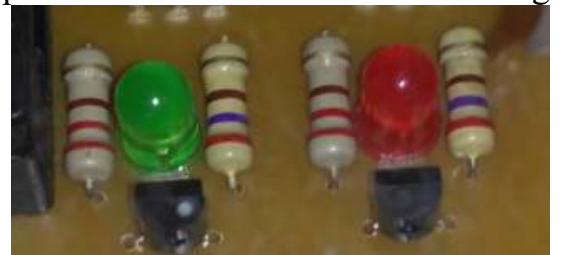

Gambar 20 Kondisi LED Keadaan Normal

\section{KESIMPULAN}

Berdasarkan hasil perancangan dan pengujian pada proyek akhir yang berjudul "Perancangan Dan Realisasi Pengatur Kadar Garam Pada Aquarium Air Laut Berbasis Mikrokontroler Atmega16" maka dapat disimpulkan bahwa: Metal keping sejajar dapat mendeteksi tegangan berdasarkan kadar garam yang terkandung didalam air. Semakin tinggi kadar garam tegangan yang di dapatkan semakin besar sedangkan semakin rendah kadar garam tegangan yang di dapat semakin kecil. Pada pengujian adanya sumber air tawar dan air laut dapat berfungsi untuk menstabilkan kadar air garam.Dari hasil pengujian didapatkan kesimpulan bahwa masing - masing komponen telah bekerja dengan baik dan alat dapat bekerja sesuai dengan rancangan.

\section{SARAN}

Beberapa saran yang dapat dikembangkan lebih lanjut diantaranya: Bahan elektroda pada sensor dapat menggunakan bahan dari platina untuk menghindari terjadinya korosi. Pertimbangan posisi dan panjang metal keping sejajar pada sensor agar lebih akurat terhadap

Perancangan dan Realisasi Pengatur Kadar Garam pada Aquarium Air Laut Berbasis Mikrokontroler ATMEGA16 (Paryanta) 
volume aquarium. Pengembangan PA(Proyek Akhir) kedepannya dapat digabungkan dengan alat pengontrol suhu dan PH pada aquarium agar suhu pada aquarium stabil sesuai habitat aslinya.

\section{DAFTAR PUSTAKA}

[1] Abdul dan Kadir. 2013. Panduan Praktis Mempelajari Aplikasi Mikrokontroler dan Pemrogramannya Menggunakan Arduino. Yogyakarta:Andi.

[2] Dajan dan Anto. 2013. Analisis Statistik Deskriptif. Jakarta: Graha Ilmu.

[3] Dayat Kurniawan. 2010. Aplikasi Elektronika Dengan Visual C\# 2008 Express Edition. Jakarta: PT. Elex Media Komputindo.

[4] Dian Artanto. 2008. Interaksi Arduino dan lab VIEW, Jakarta : Elex Media Komputindo.

[5] Jogiyanto, H.M. 2005. Sistem Teknologi Informasi. Yogyakarta: Andi Offset.

[6] John, B. 2010. Electrical And Electronic Principles And Technology". Oxford: PT. Elsevier \& Technology.

[7] Kristanto dan Andri. 2003. Bahasa Asembler. Yogyakarta: Gava Media.

[8] Rusmadi dan Dedy. 2009. Mengenal Komponen Elektronika. Bandung: Pionir Jaya.

[9] Sandy Hermawan dan Choirul Banun. 2014. Top Pocket No.1 Fisika SMA Kelas X,XI\&XII .Jakarta Selatan: PT.Wahyumedia.

[10] Suhata. 2005. VB sebagai Pusat Kendali Peralatan Elektronik. Jakarta: PT.Elex Media Komputindo.

[11] J. Supranto. 2009. Statistik Teori dan Aplikasi Edisi ke-7. Jakarta: Erlangga.

[12] Susilo dan Deddy. 2010. 48 Jam Kupas Tuntas Mikrokontroler MSC51 \& AVR. Yogyakarta: Andi.

[13] Wardhana dan Lingga. 2007. Belajar Sendiri Mikrokontroler AVR Seri ATMega8535 Simulasi, Hardware, dan Aplikasi. Yogyakarta: Andi Offset.

[14] Widodo. 2010. Embedded System Menggunakan Mikrokontroler Dan Pemrogaman C.Yogyakarta: Penerbit Andi

[15] Winarno dan Deni Arifianto. 2011. Bikin Robot itu Gampang. Jakarta Selatan: PT Kawan Pustaka.

[16] Zuhal dan Zhanggischan. 2004. Prinsip Dasar Elektronika. Jakarta: Gramedia Pustaka Utama.

[17] Lancos. 2008. PonyProg2000 Documentation. Http://www.LancOS.com. Diakses 21 Desember 2016.

GO INFOTECH: JURNAL ILMIAH STMIK AUB Vol. 25, No. 1, Juni 2019 : 35 - 42 